\title{
Da insustentabilidade do desenvolvimento Os discursos da produção de "vazios" no âmbito de um programa de cooperação internacional
}

\author{
On the unsustainability of development \\ The discourses of the production of "emptiness" in the framework of \\ an international cooperation program
}

\section{De la insostenibilidad del desarrollo}

\begin{abstract}
Los discursos de la producción de "vacios" en el marco de un programa de cooperación internacional
\end{abstract}

\author{
(1) Angela Camana ${ }^{1}$ \\ (1) Jalcione Almeida ${ }^{1}$
}

\begin{abstract}
Resumo: Este texto tem como tema central os discursos sobre desenvolvimento que circundam o Programa de Cooperação Tripartida para o Desenvolvimento Agrícola da Savana Tropical em Moçambique - ProSavana, projeto de cooperação conjunta dos governos brasileiro, japonês e moçambicano. O objetivo é interpretar como a ideia de "vazio" é produzida e reforçada no material de divulgação oficial do programa, assim como em seu Plano Diretor. Subsidiariamente, algumas entrevistas com interlocutoreschave também foram utilizadas. A reflexão mobiliza o referencial teórico-metodológico da análise do discurso de matriz francesa em diálogo com perspectivas críticas do desenvolvimento. A análise aponta para (re)produção de uma ideia de que a savana moçambicana seria um "lugar vazio", desabitado e à espera do desenvolvimento, a despeito dos sujeitos que lá estão e de suas formas próprias de existência no mundo. Ademais, ainda que o ProSavana não se pretenda formalmente um programa de "desenvolvimento sustentável", é evidente o imperativo de mobilizá-lo como tal. No entanto, parece ser uma tentativa inócua, tendo em vista a repetição de práticas a despeito da inovação no discurso predominante que nada implica em sustentabilidade.

Palavras-chave: Desenvolvimento. Insustentabilidade. Vazio. Análise do Discurso. ProSavana. Moçambique.
\end{abstract}

Abstract: This text has as its central theme the development discourses surrounding the ProSavana (Tripartite Cooperation Program for Agricultural Development of the Savannah Tropical in Mozambique), a joint cooperation project of the Brazilian, Japanese and Mozambican governments. The purpose is to interpret how the idea

\footnotetext{
${ }^{1}$ Universidade Federal do Rio Grande do Sul (Ufrgs, Porto Alegre, RS, Brasil). autores.dados_biográficos
} 
of "emptiness" is produced and reinforced in the official dissemination material of the program, as well as in its master plan. Subsidiarily, some interviews with key interlocutors were also used. The reflection mobilizes the theoretical-methodological frame of discourse analysis of French matrix in dialogue with critical perspectives of the development. The analysis points to the (re)production of an idea that the Mozambican Savannah would be an "empty place", uninhabited and waiting for development, in spite of the subjects that are there and their own forms of existence in the world. In addition, although ProSavana does not formally intend itself a sustainable development program, it is evident the imperative to mobilize it as such. However, it seems to be an innocuous attempt, in view of a repetition of practices of eviction of the innovation that does not have predominant implications that imply sustainability.

Keywords: Development. Unsustainability. Emptiness. Discourse analysis. ProSavana. Mozambique.

Resumen: Este texto tiene como tema central los discursos sobre desarrollo que circundan el ProSavana (Programa de Cooperación Tripartita para el Desarrollo Agrícola de la Sabana Tropical en Mozambique), proyecto de cooperación conjunta de los gobiernos brasileño, japonés y mozambiqueño. El objetivo es interpretar cómo la idea de "vacío" es producida y reforzada en el material de divulgación oficial del programa, así como en su plan director. Subsidiariamente, también se utilizaron algunas entrevistas con interlocutores clave. La reflexión moviliza lo referencial teórico-metodológico de análisis del discurso de matriz francesa en diálogo con perspectivas críticas del desarrollo. El análisis apunta hacia (re)producción de una idea de que la sabana mozambiqueña sería un "lugar vacío", deshabitado y a la espera del desarrollo, a pesar de los sujetos que allí están y sus formas propias de existencia en el mundo. Además, aunque el ProSavana no se pretenda formalmente un programa de "desarrollo sostenible", es evidente el imperativo de movilizarlo como tal. Sin embargo, parece ser un intento inocuo, teniendo en vista la repetición de prácticas a despecho de la innovación en el discurso predominante que nada implica en sustentabilidad.

Palabras-clave: Desarrollo. Insostenibilidad. Vacíos. Análisis del Discurso. ProSavana. Mozambique.

\section{Das inquietações: breve contexto e objeto da pesquisa}

A partir de meados do século passado pode-se observar a emergência da "questão ambiental" com um interesse global, que mobiliza conferências e articulações multinacionais em prol de "problemas comuns" como crises hídricas, o buraco na camada de ozônio e, mais recentemente, as mudanças climáticas. Esse processo de institucionalização da temática trouxe consigo imperativos de adjetivação: "verde", "ecológico", "sustentável"... - ainda que, não obstante a profusão de atributos acrescidos, permaneçam dúvidas acerca da transformação de antigas práticas, ideias e conceitos. Neste sentido é emblemático o caso do "desenvolvimento sustentável", noção consolidada 
pelo Relatório Brundtland da Comissão Mundial sobre o Meio Ambiente e Desenvolvimento (ONU, 1988 [1987]).

Assim como a própria ideia de desenvolvimento, é possível mapear a origem e o contexto no qual surge o desenvolvimento sustentável. O conteúdo de ambos os termos, entretanto, é difícil de definir: o desenvolvimento, sustentável ou não, é uma espécie de discurso que comporta múltiplos sentidos, muitos deles contraditórios entre si. Por esta mesma razão, é muito difícil negá-lo: "eu não sou contra o desenvolvimento" é uma afirmação constante, mesmo em cenários de intensos conflitos em função do próprio desenvolvimento (e seus projetos). É o que acontece no caso do Programa de Cooperação Tripartida para o Desenvolvimento Agrícola da Savana Tropical em Moçambique (ProSavana), ação conjunta dos governos brasileiro, japonês e moçambicano que, conforme o próprio nome indica, visa ao desenvolvimento agrícola na região da savana moçambicana, notadamente no Corredor de Nacala, área de cerca de 14 milhões de hectares ao norte daquele país.

Ainda que a maior parte dos interlocutores ouvidos em Moçambique argumente que não é "contra o desenvolvimento", desde seu anúncio o ProSavana tem registrado diversas tensões entre os agentes cooperantes, as organizações da sociedade civil dos três países envolvidos e, evidentemente, os camponeses e camponesas ${ }^{1}$ que habitam o Corredor de Nacala - estima-se que nesta área são quatro milhões de pessoas (Mosca; Bruna, 2015) praticantes de uma agricultura caracterizada pelo pousio. Apresentado em 2009, o ProSavana é amplamente inspirado no programa de cooperação nipo-brasileira de desenvolvimento dos cerrados (Prodecer), cuja série de projetos iniciados na década de 1970 modificou as formas de viver e cultivar na região CentroOeste do Brasil. Para além das semelhanças técnicas, gostaríamos de chamar a atenção para o fato de que o ProSavana lança mão de discursos semelhantes àqueles mobilizados quando do desejo de (re)ocupação do cerrado: a promoção do programa é cercada de falas e dados que dão conta de que a savana seria um lugar "vazio", perfeito, portanto, para as aspirações de colonização daquele espaço.

A partir dessa inquietação, o objetivo deste artigo é interpretar como a ideia de "vazio" é produzida e reforçada no material de divulgação e comunicação oficial do programa, assim como em seu Plano Diretor - textos

\footnotetext{
'Cientes de que "camponês" é um conceito caro - e contraditório - às ciências sociais, gostaríamos de registrar que utilizamos o termo como êmico. Isto é, em moçambique os atores sociais se definem enquanto camponeses e não como agricultores; mesmo suas associações são assim denominadas: União Nacional de Camponeses (Unac), União Provincial de Camponeses (UPC), entre outras.
} 
que constituem o objeto empírico desta investigação. ${ }^{2}$ Entrevistas realizadas quando do trabalho de campo ${ }^{3}$ também subsidiam a reflexão, ainda que sejam consideradas como "co-textos". ${ }_{4}^{4}$ para tanto, colocaremos em diálogo estudos críticos do desenvolvimento (Escobar, 1998; 2005; Massey, 2008) e a análise do discurso de matriz francesa (Pêcheux, 1988; Pêcheux; Fuchs, 1993), a qual aqui será assumida como referencial teórico e metodológico.

\section{Pensar a partir do Brasil, pensar a partir do cerrado}

Desde a década de 1960, o Brasil passou a experimentar um intenso processo de mudanças em seu meio rural, que transformou as formas de viver e de produzir. Confirmando as aspirações de tornar-se o "celeiro do mundo", influenciado pelas inovações técnicas propostas pela "Revolução Verde", o estado passou a fomentar o crédito, a pesquisa e a extensão rural por meio de políticas públicas e da criação de entidades (como é o caso da Embrapa). Tal movimento forjou alterações nas bases mecânica, física, biológica e química da produção agropecuária, assim como produziu diferentes maneiras de ocupar o território - hoje marcado por grandes áreas voltadas à exportação de commodities. Assim, tomou corpo o que hoje se conhece por modernização conservadora da agricultura (Delgado, 2012): modernização porque modificou, por meio de aparatos técnicos, os produtos e a forma de produzir; mas conservadora na medida em que não enfrentou os problemas e demandas sociais prementes, notadamente aqueles relacionados à concentração fundiária, mas sim conservou (e mesmo aprofundou) desigualdades sociais existentes.

Para além da intensa ação estatal, surgiram e cristalizaram-se neste período investimentos particulares e projetos de cooperação internacional, como é caso do Prodecer. Ao contar com capital público e privado, o programa se dividiu em três fases, que, com objetivos modernizantes específicos, ocuparam territórios distintos. Cabe notar que, malgrado as comunidades que habitavam o cerrado, o Prodecer embaralhava interesses distintos de brasileiros e de japoneses: ao primeiro interessava ocupar as áreas "vazias" e ampliar a produtividade, ao passo que ao segundo era conveniente uma maior

\footnotetext{
${ }^{2} \mathrm{O}$ material de divulgação é composto por um cartaz, um folheto, um folder geral sobre os projetos e uma "Mensagem chave". Todos estes documentos constam no site oficial do programa, disponibilizados na seção "Estratégia de comunicação do ProSavana".

${ }^{3} \mathrm{O}$ trabalho de campo, composto por entrevistas e observação, é parte do trabalho de tese - em andamento - da primeira autora. A estadia em Moçambique se deu em duas ocasiões: a primeira entre fevereiro e março de 2017, a segunda entre janeiro e abril de 2018.

${ }^{4}$ Compreendemos como "co-texto" aqueles textos que não fazem parte do corpus da pesquisa em questão, mas contribuem para a leitura dos discursos em análise ao passo que aportam novos dados e, mesmo, contra-discursos.
} 
oferta de grãos no mercado internacional. De acordo com Salazar Pessôa e Inocêncio (2014), esse programa foi diretamente responsável pela ocupação de cerca de 345 mil hectares do cerrado brasileiro, área maior que o território de muitos países. Ainda que se tenha produzido uma narrativa de que se tratava de uma terra vazia e estéril, portanto "disponível", é importante registrar que cerca de 50 povos indígenas habitavam aquele espaço, bem como sertanejos e camponeses (Castrillon Fernández, 2007; Fleury, 2008):

Ou seja, a "disponibilidade" dos chamados "grandes estoques" de terras, encravados nos denominados "vazios" populacionais, decorreu de um longo processo social de construção de novos territórios, processo esse pautado na desarticulação e desestruturação de territórios tradicionais de caça, pesca, roças, moradia, rituais, conflitos e lazer dos povos indígenas. Essa construção social do "despovoamento" foi mediada por relações de conflito e violência, levando à quase extinção de vários grupos [...] (Castrillon Fernández, 2007, p. 157).

A produção de disponibilidades, desse modo, é aqui compreendida como própria ao desenvolvimento, ideia-força que, para promover seus projetos (e promover-se por projetos), lança mão da homogeneização do espaço, eliminando não só o "Outro", mas toda as possibilidades de diferença. Disto decorrem conflitos (ambientais) permeados por assimetrias, em contextos nos quais seguir existindo - e tendo sua existência reconhecida - já é uma forma de resistir.

Assinado em 2009, o Memorandum de entendimento sobre a cooperação triangular para o desenvolvimento da agricultura das savanas tropicais em Moçambique, pode ser compreendido como o "ato fundador" do ProSavana. Neste breve documento a parceria trilateral é justificada a partir da experiência nipo-brasileira do Prodecer, considerada exitosa pelos países envolvidos.

O Programa de Cooperação Brasil-Japão para o Desenvolvimento Agrícola dos Cerrados Brasileiros, iniciado na década de 1970, implementou por cerca de 20 anos, projetos de Cooperação Técnica e de Cooperação Financeira, contribuindo enormemente não só para o desenvolvimento do interior do Brasil mas, também, para equilibrar a oferta e procura de alimento a nível global através do aumento da produção de alimentos. Por meio do desenvolvimento agrícola dos cerrados, o Brasil detém hoje vasto conhecimento relacionado ao desenvolvimento agrícola sustentável em zonas de savanas tropicais. [...] [Um estudo conjunto] constatou que há muitos pontos de semelhança entre o Cerrado Brasileiro e a Savana Tropical de Moçambique e que existem muitos exemplos de técnicas agrícolas que podem lhes servir de referência (ABC, 2009, p. 2). 
Ainda que não justifique a quase ausência de preocupações ambientais (o que se nota, dentre outros, no avanço do latifúndio e no uso desmedido de agrotóxicos), é importante referir que o Prodecer toma corpo num período em que o adjetivo "sustentável" não acompanhava (imperiosamente) o desenvolvimento. Não é o caso do ProSavana, que inclusive, em seu Plano Diretor $^{5}$ (Moçambique, 2015, p. 3-1 - grifos acrescidos), apresenta como visão "melhorar as condições de vida da população no Corredor de Nacala através de um desenvolvimento agrícola regional sustentável e inclusivo", em que pesem as formas pelas quais isto se dará, que são explicitadas já nas missões expostas no plano:

1. Melhorar e modernizar a agricultura com vista a um aumento da produtividade e produção, e diversificação da produção agrícola;

2. Gerar emprego através de investimentos agrícolas e do estabelecimento de cadeias de valor (Moçambique, 2015, p. 3-1).

Isto é, ainda que a forma pela qual tal movimento se dará seja questionável (especialmente no que diz respeito ao "aumento da produtividade e da produção" por meio da modernização), o "desenvolvimento sustentável" está no horizonte desse programa de desenvolvimento.

\section{O desenvolvimento (e seus projetos) como discurso}

Nesta reflexão, o ProSavana é compreendido como um megaprojeto de desenvolvimento: além de assim se narrar, as ações que prevê são grandiosas. Sustentado por uma ampla rede de atores, o programa movimenta somas vultuosas de dinheiro, bem como se estende no tempo: são previstos 20 anos de projetos, prorrogáveis. Além disso, são por ele envolvidas grandes extensões territoriais, ao abranger 20 distritos ao longo de três províncias (Zambézia, Niassa e Nampula). O programa compreende o Corredor de Nacala, o qual integra a região norte de Moçambique por meio de 912 quilômetros de malha férrea, que inicia na província de Tete, próximo do megaempreendimento de mineração promovido pela Vale S.A (Chizenga, 2016). Destes, 200 quilômetros da malha férrea atravessam o país vizinho, o Malaui, chegando à província de Niassa e cruzando toda a província de Nampula até alcançar o Oceano Índico no renovado porto de Nacala, como ilustra a Figura 1.

\footnotetext{
${ }_{5}^{5}$ O Plano Diretor possui 204 páginas, divididas em oito capítulos. As páginas não são numeradas de forma contínua; a cada capítulo inicia uma nova contagem. Por exemplo, o capítulo 2 começa em 2-1 e se estende até a página numerada como 2-42 (pois é composto por 42 páginas). No caso de citações, seguiremos a forma de paginação empregada pelo próprio documento.
} 
Figura 1. O Corredor de Nacala e o ProSavana.

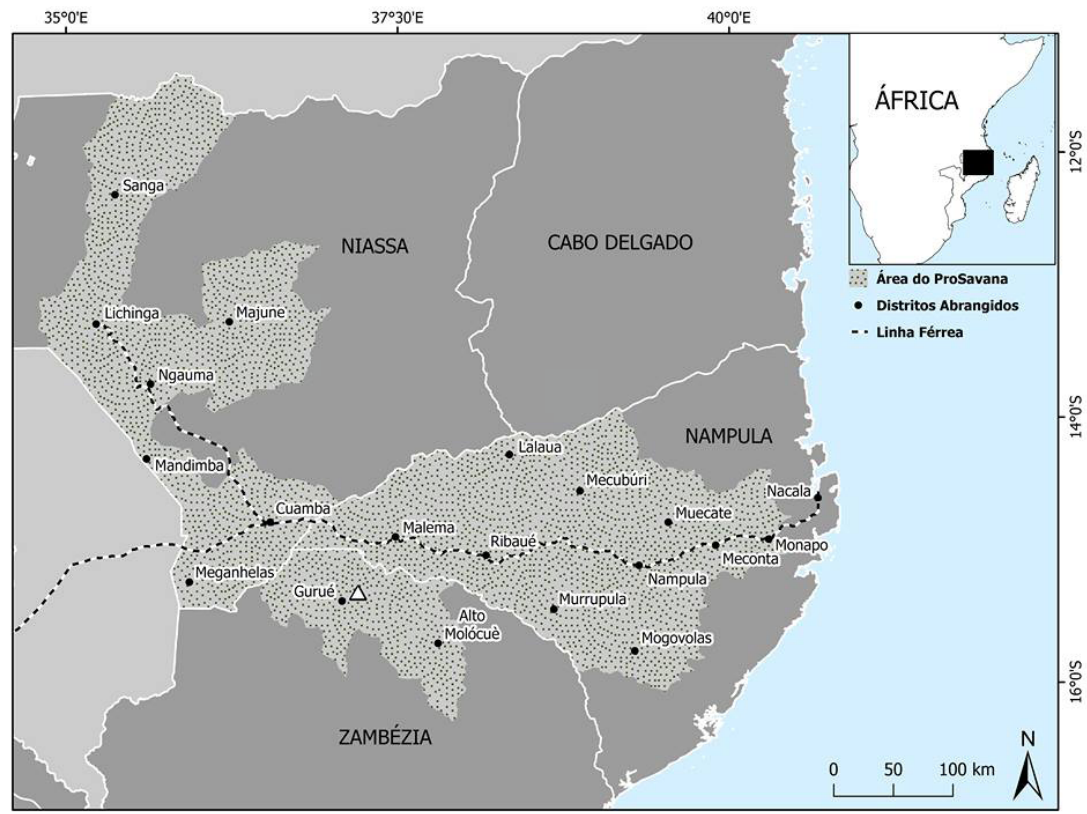

Fonte: Elaboração própria.

Ainda que pesquisas indiquem a presença de quatro milhões de pessoas ao longo do Corredor de Nacala, com diferentes línguas, costumes e formas de viver daquele e naquele lugar, tem nos inquietado a ideia - identificada em diversos documentos e textos jornalísticos de Moçambique e do Brasil - de que se trataria de um lugar vazio. A isso soma-se uma espécie de correlação obrigatória: se está vazio, é necessário ocupá-lo - daí a emergência ou imposição de grandes projetos ditos de desenvolvimento, dentre os quais o ProSavana. Dessa reflexão primeira, uma questão/problematização acompanhou nosso percurso de pesquisa: está vazio e pode/precisa ser ocupado? ou então, por que deseja-se ocupar, "esvazia-se"? Apostando nesta segunda noção, aproximamo-nos de referencial teórico de corte pós-estruturalista, que nos permite apreender os lugares como uma construção social, a qual se dá sobretudo por meio do discurso - sem com isso, ressaltamos, negar a materialidade do espaço (Massey, 2008).

Assim, nos interessa analisar os discursos oficiais sobre o ProSavana, especialmente seu Plano Diretor e seu material de divulgação. Para tanto, operamos com a análise do discurso (AD) de matriz francesa, conforme proposta por Michel Pêcheux (1988) e colaboradores. Não entendemos a AD como 
um procedimento unicamente metodológico, mas sim como um referencial teórico que oferece ferramentas conceituais e analíticas. Dessa concepção temos que a $\mathrm{AD}$ é estabelecida no encontro de reflexões provenientes de três grandes áreas, das quais toma de empréstimo conceitos centrais: da linguística, questiona-se a centralidade da língua, assumindo o discurso como objeto; da psicanálise, o sujeito (contraditório e fragmentado, ainda que se deseje uno); e do materialismo histórico, a ideologia (que interpela os indivíduos enquanto sujeitos). Com esta tríade, a AD nos convida a refletir sobre como e desde que lugar pensamos o que pensamos, ou seja, ponderarmos acerca das condições de produção do discurso - há, portanto, uma virada, pois o discurso passa a ser compreendido enquanto processo e não, a exemplo do que proporia a linguística saussuriana tradicional, como produto.

Assumindo o discurso como objeto, esse é apreendido a partir do texto (que não necessariamente corresponde a um documento escrito): em termos práticos, é o olhar discursivo que converte o texto em discurso, por intermédio de um gesto de leitura atento e sensível. Assim, conforme Pêcheux e Fuchs (1993), a AD se configura como uma análise não subjetiva da subjetividade. Isso porque, embora reconheça que a língua é opaca, de forma que os sentidos deslizam/deslocam-se e os sentidos possíveis de um texto possam ser vários, eles não são todos, nem qualquer um (Indursky, 2008). Assumindo o que propõe a $\mathrm{AD}$, portanto, um mesmo texto (ou fala) pode trazer em si diferentes discursos, que nem sempre são coerentes ou lineares - a exemplo do próprio sujeito que discursiviza. A este respeito Pêcheux (1988) sugere o conceito de formação discursiva (FD), como sendo aquilo que pode e deve ser dito desde uma formação ideológica específica.

Com isso, admitimos que os sentidos não estão nas palavras ou no texto em si, mas só podem ser apreendidos ao se identificarem as FDs desde onde são produzidas. Encaramos, por conseguinte, as FDs como o locus no qual se discursivizam certas ideologias e saberes. Para esta investigação, tomamos como ferramenta analítica a identificação de FDs sobre desenvolvimento presentes no material em análise, a fim de, extrapolando-as, refletirmos sobre os saberes ideológicos que as possibilitaram.

No objeto empírico em análise, após gesto de leitura, identificamos uma formação discursiva predominante, a qual traz em si inscritos saberes que reificam a ideia de que quaisquer práticas e formas de viver dissonantes das tidas como "modernas" configurariam o "atraso" da região a ser ocupada pelo ProSavana. Há um discurso sobre desenvolvimento ancorado em valores como a produtividade (e o imperativo de seu permanente aumento), a qual só pode se dar por meio da adoção de tecnologias modernas, tais como aquelas do período 
da modernização da agricultura no Brasil, quais sejam: o uso de maquinário, de sementes "melhoradas" (sendo elas híbridas e/ou transgênicas'), de fertilizantes químicos e agrotóxicos, da irrigação. Isso é apreendido em sequências discursivas recortadas do Plano Diretor do ProSavana:

A maioria dos produtores do Corredor de Nacala é de pequena escala e pratica a agricultura de subsistência. Devido à baixa produtividade, actividade de pequena escala e falta de mercados para a comercialização dos seus produtos, o benefício da agricultura para os produtores é limitado. Assim, os produtores não têm recursos financeiros para a aquisição de insumos agrícolas. Outrossim, têm um acesso limitado ao conhecimento e a tecnologia agrícola moderna, o que restringe a capacidade de aumento da produtividade e por consequência a melhoria dos meios de subsistência. (Moçambique, 2015, p. 2-38 - grifos acrescidos).

A incidência da pobreza em Moçambique melhorou entre $1996 \mathrm{e}$ 2003 , caindo de $69,4 \%$ para $54,1 \%$. No entanto, entre 2003 e 2009, a incidência da pobreza permaneceu quase inalterada. A incidência da pobreza da província da Zambézia aumentou de 44,6\% em 2003 para $70,5 \%$ em 2009, que foi o pior do país. Na província de Nampula a incidência da pobreza também ficou um pouco pior, passando de $52,6 \%$ em 2003 para 54,7\% em 2009. Por outro lado, a incidência da pobreza na província de Niassa melhorou significativamente, reduzindo de 52,1\% em 2003 para 31,9\% em 2009. Assume-se como sendo a causa da deterioração da incidência da pobreza em 2008 a queda significativa no sector agrícola devido ao [mau] tempo fora de época. Deste modo, compreende-se que a estabilidade de produção agrícola pode contribuir de forma significativa para a melhoria da incidência da pobreza em áreas onde a agricultura é a principal actividade. (Moçambique, 2015, p. 2-28 - grifos acrescidos).

Isto é, o Plano Diretor do programa caracteriza a região do Corredor de Nacala como pobre e atrasada, assumindo que o "desenvolvimento" - agrícola, mas não apenas - só se dará por meio da modernização tecnológica dos meios de produção. Reduz-se, portanto, os "problemas" da região a uma questão tecnológica, tal como propõe Ferguson (1990) na já clássica noção de desenvolvimento como máquina antipolítica. ${ }^{7}$ Além disso, em diálogo com Escobar (1998; 2005), a análise empreendida indica que, para os saberes discursivisados no escopo desta FD, todas as formas diferentes de produzir, e mesmo de existir no mundo, são consideradas atrasadas e, portanto, passíveis de

\footnotetext{
${ }^{6}$ Ainda que em Moçambique não seja permitido o plantio comercial de organismos geneticamente modificados (OGMs), os transgênicos, não é vedada a pesquisa com estas variedades.

${ }^{7}$ Com esta metáfora Ferguson (1990) descreve a maneira pela qual o desenvolvimento opera, colocando em "suspenso" todas as tensões próprias daquilo que é propriamente político.
} 
"receberem" ações de desenvolvimento. Ou seja, ao descrevê-lo como pobre e atrasado, o Corredor de Nacala é produzido como um lugar vazio (de desenvolvimento). Se isso é perceptível no texto do Plano Diretor, esta ideia se apresenta com outra linguagem (mas sentidos muito próximos) em um pôster que compõe o material de divulgação oficial do Programa (Figura 2), cujo públicoalvo é mesmo aquele entendido como "beneficiário" das ações do ProSavana.

Figura 2. Pôster de divulgação do ProSavana.

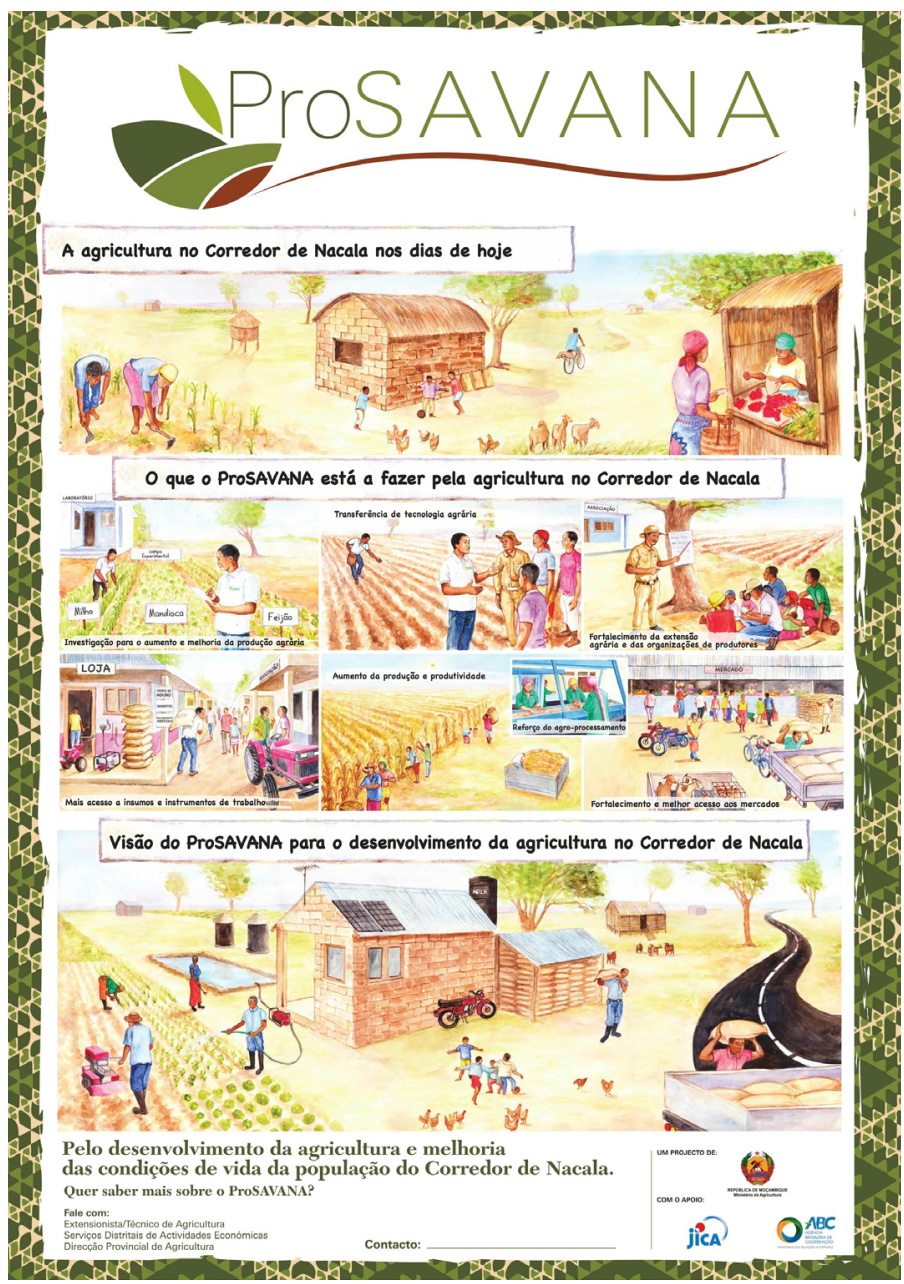

Fonte: ProSavana

$<$ www.prosavana.gov.mz/wp- content/uploads/2015/04/FinalPosterPT1.pdf> (18 set. 2018). 
Nessa imagem, resta evidente uma noção de progresso/evolução, tradicionalmente cara ao desenvolvimento. Note-se que a passagem de uma "etapa" a outra (narrada como moderna, um ideal a ser alcançado) se dá quase que unicamente por meio do incremento da produtividade. Esse feito se conquistaria por meio da adoção de novas técnicas e tecnologias, bem como pela adequação dos sujeitos a formas de cultivo específicas (ideia expressa na educação por meio da extensão rural).

No primeiro quadro (“A agricultura no Corredor de Nacala nos dias de hoje") podemos observar, dentre outros elementos, uma representação da atual cadeia produtiva: no lado esquerdo, há a produção do que parece ser milho, por meio da enxada de cabo curto, instrumento tradicionalmente utilizado na região do Corredor de Nacala. Já no lado direito, notamos mulheres camponesas vendendo e adquirindo produtos in natura, enquanto crianças brincam entre animais soltos ao redor da propriedade. Fica evidente que há algo lá, mas, talvez, sejam modos de viver e de produzir inadequados às perspectivas de modernidade e desenvolvimento desejadas pelos promotores do ProSavana.

Assim, ainda que existam naturezas, sujeitos e formas de viver e ocupar esse lugar, o Corredor de Nacala segue sendo apresentado como um espaço a ser necessariamente (re)ocupado. Isso encontra respaldo em dados como os já apresentados (indicadores de pobreza e produtividade, entre outros) e se reforça em falas de dirigentes da região, as quais são reproduzidas nos jornais: "Espaço é o que temos demais", é o título de uma reportagem publicada em 3 de outubro de 2013, no Jornal Notícias, o maior em circulação em Moçambique, na qual agentes do estado convidam produtores a engajarem-se no ProSavana.

Assim, retomamos as contribuições de Escobar (1998; 2005), as quais dão conta, dentre outras questões, de que se identifique que não só o desenvolvimento gera efeitos a posteriori (que podem ser avaliados depois da implementação de programas específicos), como também produz o próprio lugar apto a "recebê-lo". Disso decorre a ideia de que existem "lugares desenvolvíveis" ("developmentalizable”), que em geral são caracterizados a partir da falta: são "vazios" e "atrasados", visto que carecem de ocupação (ou melhor, de uma ocupação bastante específica) para "avançarem" na fila da história (Massey, 2008). Ao descrever o Corredor de Nacala como pobre, atrasado e vazio, o discurso oficial do ProSavana corrobora para que essa seja a principal maneira de observá-lo. Esta espécie de modus operandi do desenvolvimento corresponde àquilo que também se percebeu no processo de ocupação do cerrado brasileiro pelo agronegócio: 
Quando se analisa o longo processo de ocupação da Amazônia brasileira e, de modo particular, do estado de Mato Grosso, observa-se que a ideia da "disponibilidade" de "grande estoque de terra" resultou de uma prática discursiva que procurava evidenciar a existência de "vazios demográficos", empregada por sucessivos governos e setores empresariais empenhados em reocupar esses territórios, tradicionalmente ocupados por povos indígenas e outros grupos sociais. Para colocar em curso os seus empreendimentos, foi necessário produzir tal "disponibilidade". É nesse sentido que a "terra" deve ser compreendida como o produto de relações sociais, em que o acesso de "alguns" ocorre pela negação de "outros", sem antes passar por uma mediação de intensas relações conflitivas. Ou seja, "terra" não é um bem natural, naturalmente dado, mas é um produto social, socialmente construido, e a sua disponibilidade dependeu dessa construção (Castrillon Fernández, 2007, p. 174 - grifos acrescidos).

Mais de meio século e um oceano separam o Prodecer e o ProSavana, no entanto, mais que um bioma, esses programas se aproximam pela maneira como produzem as condições de possibilidade para que eles próprios aconteçam no espaço. O que se nota, a partir de leituras do Plano Diretor e do material de divulgação oficial do ProSavana, é uma espécie de planificação do espaço, apagando diferenças de modo a permitir a implementação de grandes projetos com vistas ao chamado "desenvolvimento", ainda que esse nunca se realize. Cabe ressaltar que esta homogeneização e caracterização dos lugares como "vazios", seja o cerrado ou a savana, só pode se dar como uma produção discursiva: por sua definição, os lugares são sempre a esfera da multiplicidade de trajetórias, dos encontros e da provisoriedade - noutros termos, concebemos o lugar como o espaço da "simultaneidade de estóriasaté-agora" (Massey, 2008, p. 49).

\section{"Eu vivia neste lugar": um corredor que se faz ver}

Esta percepção de que o Corredor de Nacala seria um lugar a ser ocupado pelo agronegócio internacional encontrou forte resistência, seja por parte dos sujeitos que lá vivem ou por parte de observadores internacionais vinculados a movimentos sociais e também ao meio acadêmico, que questionaram o suposto vazio que o caracterizava.

A densidade demográfica no Cerrado no início do Prodecer era de 2,5 pessoas $/ \mathrm{km}^{2}$, enquanto nos 14 distritos do Corredor Nacala ${ }^{8}$, a densidade populacional em 2011 é de 56,2 pessoas $/ \mathrm{km}^{2}$, chegando ao máximo de 97,2 pessoas $/ \mathrm{km}^{2}$ no Distrito de Monapo (Mosca e Bruna, 2015, p. 11).

\footnotetext{
${ }^{8}$ Atualmente já são 20 distritos previstos.
} 
É importante notar também que o conhecimento público do ProSavana e de suas intenções se deu alguns anos após seu lançamento oficial, por meio de entrevistas concedidas por brasileiros a veículos de jornalismo nacionais, nas quais representantes do agronegócio anunciavam a articulação realizada para investirem no Corredor de Nacala. Diante desta notícia, interlocutores moçambicanos comentam que buscaram mais dados junto ao estado, sem sucesso. Em meio à falta de informações oficiais, estabeleceu-se um intenso conflito, cuja maior expressão talvez seja a criação da "Campanha Não ao ProSavana", que reúne diversas entidades contrárias ao programa e ao modelo de desenvolvimento que ele traz consigo. Esta campanha, assim como diversos estudos que vêm sendo realizados sobre a questão, alertam para os riscos oferecidos pelo ProSavana, em especial no que diz respeito à concentração da propriedade da terra.

Nesta seara, um elemento distintivo do cenário conflituoso no que toca à ocupação do Corredor de Nacala se dá na esfera jurídica: em Moçambique, a terra é pública e não pode ser vendida. Diz a Constituição do país:

A terra é propriedade do estado. A terra não deve ser vendida, ou por qualquer outra forma alienada, nem hipotecada ou penhorada. Como meio universal de criação da riqueza e do bem-estar social, o uso e aproveitamento da terra é direito de todo o povo moçambicano. $\mathrm{O}$ Estado determina as condições de uso e aproveitamento da terra. $\mathrm{O}$ direito de uso e aproveitamento da terra [Duat] é conferido às pessoas singulares ou colectivas tendo em conta o seu fim social ou económico (Moçambique, 2004, p. 31-32 - grifos acrescidos).

É importante notar que, ainda que a legislação preveja a outorga de Duats (Direito de Uso e Aproveitamento da Terra) a indivíduos e comunidades, a posse deste documento não é obrigatória. ${ }^{9}$ Além disso, sujeitos e empreendimentos estrangeiros podem obter Duat mediante o pagamento de taxas e a comprovação da disponibilidade da terra. Ou seja, se ao estado cabe a gestão da terra, também a ele cabe desapropriar os sujeitos que nela se encontram em prol de um "fim social ou econômico". É neste ponto que recaem as dúvidas sobre os interesses do ProSavana, de modo que o receio de perderem seu lugar é constante para aqueles que vivem ao longo da área abrangida pelo programa; além de já se ter materializado em alguns casos.

Dizem que o ProSavana aconteceu no Brasil com o nome de cerrado [o Prodecer]. Como foi no Brasil? As pessoas perderam a terra? (Entrevista com grupo de camponeses. Monapo, fev. 2018).

\footnotetext{
${ }^{9}$ Está fora do escopo deste trabalho abordar o funcionamento e as limitações da concessão de Duats. A este respeito sugerimos: Serra e Carrilho (2013) e Mandamule (2015).
} 
É isso que eu estou a dizer: não tem terra abandonada aqui. Não tem terra que não se usa. Não temos. E nós também... a terra não estamos só a usar para nós. Nós estamos a cuidar da terra, contando com a nossa futura geração. (Entrevista com liderança camponesa da província de Nampula. Nampula, mar. 2017).

Nos primeiros dias, quando vieram aqui, quando encontraram as pessoas, na justificação deles [para solicitar o Duat] disseram "nós apenas encontramos aqui três pessoas". Três pessoas! [risos]. [...] Há muita gente nesta comunidade, mas a empresa diz que achou só três. Não pode ser! (Camponês. Entrevista. Malema, fev. 2018).

Neste sentido, o próprio Plano Diretor do programa, ao buscar se esquivar desta ordem de denúncias, abre margem para dúvidas:

Os sistemas consuetudinários de gestão da terra geridos pelos lideres tradicionais serão respeitados; entretanto, serão feitas intervenções necessárias visando uma melhor governação da terra, em termos de sua alocação, igualdade de géneros, acerto de disputas e negociações com investidores (Moçambique, 2015, p. 6-1 - grifos acrescidos).

Note-se ainda que, no mesmo período em que o ProSavana foi lançado, estava em evidência a discussão sobre o fenômeno crescente do "saque global de terras" (global land grabbing). Isto é, na esteira das crises alimentar e energética, países "ricos em capital, mas pobres em recursos" (Zoomers, 2013, p. 14) passaram a procurar grandes extensões de terra fértil para monocultivos de commodities agrícolas, especialmente no continente africano. Pensando especificamente no caso de Moçambique, esta autora atenta para a repetição do esvaziamento do espaço, alertando para os riscos observados em processos de "desenvolvimento" pregressos:

[...] a colonização agrícola (década de 1970-80s) expôs o mito de terras vazias, bem como o impacto ambiental devastador de estratégias horizontais que levaram ao [desflorestamento e à degradação ambiental. (...] É relevante saber como o desenvolvimento actual se relaciona com os percursos anteriores do desenvolvimento (é mais do mesmo ou é oposto aos desenvolvimentos anteriores?) (Zoomers, 2013, p. 37).

Como já argumentado, o discurso não é apenas um modo de narrar o mundo, mas também é capaz de produzi-lo. Assim, ainda que milhares de sujeitos se insurjam e, amparados por movimentos sociais, produções acadêmicas e articulações internacionais, demonstrem que estão lá, há que 
se observar se tais produções serão suficientes para "apagar" o sentido de esvaziamento dado até então. Que desenvolvimento é esse, então? O que ele tem de sustentável? Essas são questões que transbordam quando da experiência do ProSavana, principalmente quando os discursos oficiais se encontram com àqueles dos que o recusam e, por que não, resistem.

\section{O discurso do desenvolvimento: há "esvaziamento" sustentável?}

Esta reflexão se debruçou sobre o discurso do desenvolvimento na experiência do ProSavana, tomando como objeto empírico o Plano Diretor e o material oficial de divulgação desse programa. Em especial discutimos a produção discursiva da categoria de "vazio", a qual é mobilizada como justificativa para a implementação de grandes ações de desenvolvimento agrícola, as quais muitas vezes implicam na desapropriação de camponeses e camponesas. Compreendemos, desde os estudos sobre o discurso, que a apresentação ou mobilização de dados e índices (como os da pobreza e da ocupação demográfica) não constitui uma descrição inócua, mas é uma forma de construir um determinado espaço. Ainda desde as proposições da análise de discurso, desdobradas em diálogo com Escobar (1998; 2005) e Massey (2008), temos que o próprio desenvolvimento é uma produção discursiva, de modo que buscamos tomá-lo como objeto em uma mirada crítica.

A emergência de um discurso sobre desenvolvimento sustentável chamou a atenção para o "Outro" do desenvolvimento (e das teorizações sobre ele): o ambiente. No entanto, podemos conceber que uma visão bastante específica (e estreita) daquilo a ser "sustentado"/preservado pode ser encaixada nessa ideia, a despeito da multiplicidade de formas possíveis de se compor o espaço. O "desenvolvimento sustentável", assim, ocupa-se de uma natureza bastante singular, a ser explorada por sujeitos inseridos em um modo de produção igualmente específico. Tudo aquilo (e aqueles) que não pode ser enquadrado nesta ordem - isto é, os diferentes e a diferença - pode ser desconsiderado: surge o "vazio", marcado pelo "atraso" e pela "pobreza".

No entanto, do ponto de vista teórico por nós empreendido, um lugar jamais é, por si só, "vazio": há que ser produzido dessa maneira. Compreendendo o desenvolvimento como uma produção discursiva (da qual decorrem, evidentemente, efeitos materiais), é por meio e por interesse dele que se "esvaziam" os espaços - e isso acontece sendo o desenvolvimento "sustentável" ou não, como notamos no caso do Prodecer e do ProSavana. Com isso não queremos incorrer no equívoco de apresentar esses casos como se fossem o mesmo ou partes de um mesmo processo, apenas buscamos 
identificar as regularidades de um discurso que se repete, trazendo em si uma memória de destituição de existências (do cerrado e daqueles que lá viviam).

Parece-nos interessante notar que, ainda que o ProSavana não se pretenda um programa no âmbito do "desenvolvimento sustentável", ele próprio em seus discursos oficiais - lança mão dessa ideia. Mas o que o sustentável acrescenta a este processo? Mais do que o adjetivo adiciona ou extrai à ideia, é perceptível o imperativo de mobilizá-lo, o que denota uma espécie de "pacto global": no entanto, parece ser um acordo inócuo, tendo em vista a repetição de práticas a despeito da inovação no discurso - o que sequer acontece no caso do ProSavana, cujo discurso predominante nada implica em sustentabilidade.

Neste sentido, um caminho analítico possível se dá a partir da contribuição de teóricos vinculados ao pós-desenvolvimento, a qual não só questiona a pertinência de seguirmos disputando os sentidos de "desenvolvimento sustentável", como argumenta pelo abandono da própria ideia de desenvolvimento. De acordo com Esteva (2000), a inclusão de adjetivos já denota a falência do projeto de desenvolvimento; noutros termos, o "sustentável" não é capaz de alterar aquilo que essa ideia-força produz: ainda se trata do desenvolvimento (cf. Latouche, 2007).

Ainda assim, mesmo com o encaminhamento da potente crítica e discussão teórica trazida pelo pós-desenvolvimento, há que se considerar que - deixando ou não de tomá-lo como objeto - o desenvolvimento ainda produz efeitos no mundo, muitos deles nefastos. Nesse sentido, a emergência de conflitos ambientais em torno de megaempreendimentos como o ProSavana pode ser encarada como parte de uma disputa mais ampla, que dá conta de fazer o "desenvolvimento" (e aqueles que o promovem) se defrontar com formas outras de estar no mundo e compor os lugares, que nada têm de "vazias".

\section{Referências}

ABC. Memorandum de entendimento sobre a cooperação triangular para o desenvolvimento da agricultura das savanas tropicais em Moçambique. Ata da reunião realizada no dia 17 de setembro de 2009. Documento interno. Disponível em: www. prosavana.gov.mz/wp-content/uploads/2015/04/17-set-2009-P1.pdf. Acesso em: 30 mar. 2017. https://doi.org/10.17528/cifor/006293

CASTRILLON FERNÁNDEZ, Antonio João. Do cerrado à Amazônia: as estruturas sociais da economia da soja em Mato Grosso. 2007. Tese (Doutorado em Desenvolvimento Rural) - Faculdade de Ciências Econômicas, UFRGS, Porto Alegre, 2007. Disponível em: http://hdl.handle.net/10183/14276. Acesso em: 26 set. 2018. https://doi.org/10.11606/t.11.2016.tde-28042016-145545 
CHIZENGA, Anselmo P. Mineração e conflito ambiental: disputas em torno da implantação do megaprojeto da Vale na bacia carbonífera de Moatize, Moçambique. Dissertação (Mestrado em Sociologia) - UFRGS, Porto Alegre, 2016. Disponível em: http://hdl.handle.net/10183/155999. Acesso em: 26 set. 2018. https://doi.org/ $10.5007 / 1984-9222.2015$ v7n14p167

DELGADO, Guilherme C. Do capital financeiro na agricultura à economia do agronegócio: mudanças cíclicas em meio século (1965-2012). Porto Alegre: Editora da Ufrgs, 2012.

ESCOBAR, Arturo. El "postdesarrollo" como concepto y práctica social. In: MATO, Daniel (org.). Políticas de economía, ambiente y sociedad en tiempos de globalización. Caracas: Universidad Central de Venezuela, 2005. p. 17-31.

ESCOBAR, Arturo. La invención del Tercer Mundo: construcción y deconstrucción del desarrollo. Bogotá: Norma, 1998.

ESTEVA, Gustavo. Desenvolvimento. In: SACHS, Wolfgang (org.). Dicionário do desenvolvimento. Petropolis: Vozes, 2000. p. 59-83.

FERGUSON, James. The anti-politics machine: "development", depoliticization and bureaucratic power in Lesotho. Cambridge: Cambridge University Press, 1990. https://doi.org/10.1002/jid.3380040314

FLEURY, Lorena C. Cerrado para ser o quê? Representações sociais e conflitos ambientais em torno do Parque Nacional das Emas, Goiás. 2008. Dissertação (Mestrado em Desenvolvimento Rural) - Faculdade de Ciências Econômicas, UFRGS, Porto Alegre, 2008. Disponível em: http://hdl.handle.net/10183/14898. Acesso em: 26 set. 2018. https://doi.org/10.11606/t.91.2005.tde-09112005-144620

INDURSKY, Freda. Unicidade, desdobramento, fragmentação: a trajetória da noção de sujeito na análise do discurso. In: MITTMANN, Solange; GRIGOLETTO, Evandra; CAZARIN, Ercília Ana (org.). Práticas discursivas e identitárias: sujeito e língua. Porto Alegre: Nova Prova, 2008. p. 9-33.

LATOUCHE, Serge. Sobrevivir al desarrollo. Barcelona: Icaria, 2007.

MANDAMULE, Uacitissa. Discursos à volta do regime de propriedade da terra em Moçambique.ObservadorRural (OMR).n.32, set.2015.(Workingpaper)Disponívelem: http://omrmz.org/omrweb/publicacoes/observador-rural-32/. Acesso em: 26 set. 2018.

MOÇAMBIQUE. Ministério da Agricultura e Segurança Alimentar. Plano Director para o Desenvolvimento Agrário do Corredor de Nacala em Moçambique. Esboço Versão 0. Mar. 2015. Maputo: Masa, 2015. Disponível em: www.prosavana.gov. mz/wp- content/uploads/2015/09/1.Master_Plan_Draft_Zero_Main_Revisao1.pdf. Acesso em: 31 maio 2017. https://doi.org/10.17528/cifor/006293

MOÇAMBIQUE. Constituição [2004]. Constituição da República. Maputo: 2004.

MASSEY, Doreen. Pelo espaço: uma nova política da espacialidade. Rio de Janeiro: Bertrand Brasil, 2008. https://doi.org/10.5216/bgg.v29i1.7106 
MOSCA, João; BRUNA, Natacha. ProSavana: discursos, práticas e realidades. Observador Rural (OMR). n. 31, ago. 2015 (Working paper). Disponível em: http:// omrmz.org/omrweb/publicacoes/observador-rural-31//. Acesso em: 26 set. 2018.

ORGANIZAÇÃO das Nações Unidas (ONU). Comissão Mundial sobre Meio Ambiente e Desenvolvimento. Nosso futuro comum. Rio de Janeiro: Fundação Getulio Vargas, 1988. [1987].

PÊCHEUX, Michel; FUCHS, Catherine. A propósito da análise automática do discurso: atualização e perspectivas. In: GADET, Françoise; HAK, Tony (org.). Por uma análise automática do discurso: uma introdução à obra de Michel Pêcheux. 2. ed. Campinas: Unicamp, 1993. p. 163-187. https://doi.org/10.1590/s0103-37862007 000300001

PÊCHEUX, Michel. Semântica e discurso: uma crítica à afirmação do óbvio. Campinas: Editora da Unicamp, 1988.

SALAZAR PESSÔA, Vera Lúcia; INOCÊNCIO, Maria E. O Prodecer (re)visitado: as engrenagens da territorialização do capital no Cerrado. Campo-Território: Revista de Geografia Agrária. Edição especial do 21 Enga-2012, p. 1-22, jun. 2014.

SERRA, Carlos Manuel; CARRILHO, João. Dinâmicas da ocupação e do uso da terra em Moçambique. Maputo: Escola Editora, 2013.

ZOOMERS, Annelies. Lidar com a corrida global à terra: uma análise crítica das políticas rurais sobre a terra, desde os anos 50. In: Carlos Manuel Serra; João Carrilho. Dinâmicas da ocupação e do uso da terra em Moçambique. Maputo: Escola Editora, 2013. p. 13-50. https://doi.org/10.11606/t.91.2007.tde-16032007-165103

Recebido em: 26 set. 2018

Aprovado em: 13 mar. 2019

Publicado em: 30 jul. 2019

Autora correspondente:

Ângela Camana

Av. Bento Gonçalves 9500 - Agronomia

90650-000, Porto Alegre, RS, Brasil

ÂNGELA CAMANA <angela.camana@hotmail.com>

Doutoranda em Sociologia na Universidade Federal do Rio Grande do Sul (Ufrgs) em Porto Alegre, RS, Brasil. É bolsista Capes, integrante do grupo de pesquisa Tecnologia, Meio Ambiente e Sociedade (Temas) e do grupo de pesquisa Jornalismo Ambiental na mesma universidade.

Orcid: http://orcid.org/0000-0002-1924-2144

JALCIONE ALMEIDA <jal@ufrgs.br>

Doutor em Sociologia pela Université Paris (Paris, França), professor titular da Universidade Federal do Rio Grande do Sul (Ufrgs) em Porto Alegre, RS, Brasil, atua nos PPGs em Sociologia e Desenvolvimento Rural, coordena o grupo de pesquisa Tecnologia, Meio Ambiente e Sociedade (Temas), é pesquisador do CNPq.

Orcid: https://orcid.org/0000-0002-8915-0579 